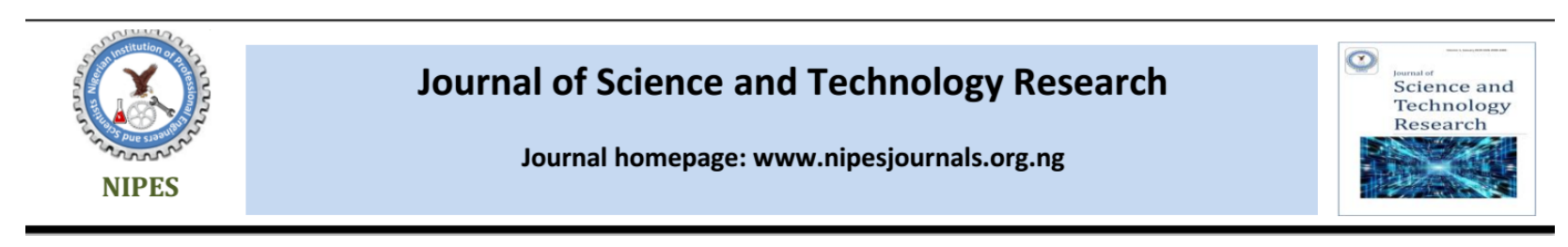

\title{
Climate Change: The Contributing and Mitigating Impact of Plastic Materials
}

\section{Oludaisi Adekomaya}

Olabisi Onabanjo University, Department of Mechanical Engineering, Ogun State, Nigeria

\begin{tabular}{|c|c|}
\hline Article Info & Abstract \\
\hline $\begin{array}{l}\text { Keywords: } \\
\text { plastic waste, climate change, } \\
\text { emission, environment, global } \\
\text { warming }\end{array}$ & $\begin{array}{l}\text { Plastic materials have increased in recent times in view of their } \\
\text { application in structures and other developmental projects. While the } \\
\text { environmental impacts of plastic materials have defiled all known } \\
\text { solutions, it is equally pertinent to reiterate their environmental }\end{array}$ \\
\hline $\begin{array}{l}\text { Received } 13 \text { April } 2020 \\
\text { Revised } 24 \text { April } 2020 \\
\text { Accepted } 02 \text { May } 2020 \\
\text { Available online } 1 \text { June } 2020\end{array}$ & $\begin{array}{l}\text { materials have been investigated with many shortcomings reported } \\
\text { in published works. Part of the IPCC (Intergovernmental Panel on } \\
\text { Climate Change) findings showed that one of the critical risk factor } \\
\text { of climate change may not be unconnected with the proliferation of } \\
\text { non-biodegradable materials. This will definitely put used-plastics as } \\
\text { a disastrous material, posing dangerous threat to climate. In this } \\
\text { work, plastics waste materials were x-rayed as a potential risk } \\
\text { factors to climate change using existing data to justify their }\end{array}$ \\
\hline COP Crossref & $\begin{array}{l}\text { environmental unfriendliness. Further discussions were reported on } \\
\text { each disposal option of plastic wastes including their waste volume } \\
\text { as captured by IPCC. It is also noted in this review paper what }\end{array}$ \\
\hline $\begin{array}{l}\text { https://nipesjournals.org.ng } \\
\text { ISSN-2682-5821/@ 2020 NIPES Pub. } \\
\text { All rights reserved. }\end{array}$ & $\begin{array}{l}\text { needed to be done to mitigate emissions taking into consideration key } \\
\text { treatment methods and net emission emanating from respective } \\
\text { disposal options. It is expected that this paper will assist } \\
\text { environmentalists to devise appropriate management strategy for } \\
\text { plastic waste in order to curb the imminent climate disaster. }\end{array}$ \\
\hline
\end{tabular}

\section{Introduction}

The rising ambient temperature and the need to preserve the biodiversity structure has necessitated various intergovernmental panels on climate change to evolve sustainable approaches on the mitigation of greenhouse gas emission [1]. Global warming is the worst depleting factor of ozone layer as reported in various published works [2-4]. Plastic waste and the proliferation of nonbiodegradable materials is a major concern to environmentalists in view of difficulty in their recyclability. The worsening global temperature despite various measures to curb rising temperature has reached a stage where every researcher needs to probe further into other sources of degradation of climate change [5]. Carbon emission from waste and use of fossil fuel are among the contributing factors in the 20th century [6]. Part of the findings reported by IPCC on Climate Change showed that excessive utilization of plastic materials is instrumental to vulnerability of environment in most developing countries of Africa [7,8]. This invariably raises ambient temperature thereby inflicting environmental instability [4,9]. Couth and Trois [10] investigated environmental impact assessment of plastic waste as contained in US study on environmental data dated 2004 and showed that American citizens generated $20.6 \mathrm{tCO}_{2}$ per capita, which is almost over 150 times the reported figure of 0.1 tCO2 per capita in some part of sub-Saharan Africa. This finding can also be related to the conclusion drawn by other authors [25] which involved analysis of waste volume generated by respective disposal approach as shown in Figure 1. In all the approaches, tons per capital remains 
virtually constant indicating that the economic returns on each of the disposal methods are insignificant and equal in all cases.

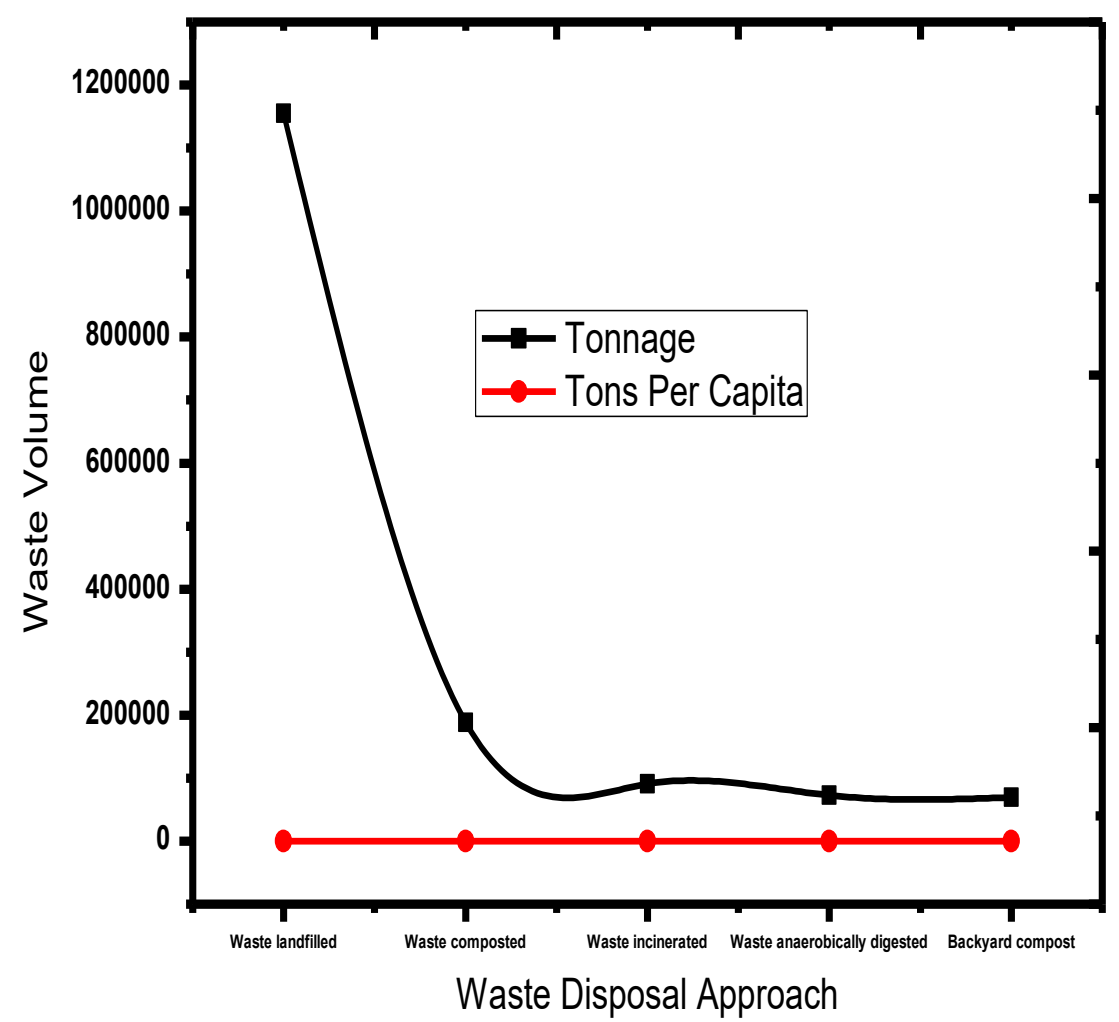

Figure 1: Waste generation from disposal options. Data were adapted [25] as contained in the IPCC 1996 and IPCC 2006 accredited reports on waste generation in USA

In the same paper, Couth and Trois (2011) further showed that the rising carbon emissions in Chad Republic alone was about $0.0127 \mathrm{tCO}_{2}$ per capita as against the mean of $1.0215 \mathrm{tCO}_{2}$ per capita in remote sub-Sahara Africa. Rigamonti, et al. [11] equally reported that the ever-increasing plastic materials and the attendant emission may poise a dangerous dimension in these areas as currently being witnessed. This was also documented in the data provided by Couth and Trois (2011) where the quantity of emissions $\left(\mathrm{tCO}_{2}\right)$ per capita produced in Africa were compared with the rest of the world as shown in Table 1. The implication of the analysis is that sub-Sahara Africa need to take a pragmatic approach to contain non-biodegradable waste as she currently has about $12 \%$ of the world's population, with less than $3 \%$ of the global carbon emission.

Table 1: Analysis of world's population and their attendant carbon emissions. Adapted from [10]

\begin{tabular}{llllll}
\hline Location & Population & $\begin{array}{l}\text { Mean } \mathrm{CO}_{2} \mathrm{e} \\
\text { t/capita }\end{array}$ & $\begin{array}{l}\text { Total }(\mathrm{Gt} \\
\left.\mathrm{CO}_{2} \mathrm{e}\right)\end{array}$ & $\begin{array}{l}\text { Percentage } \mathrm{CO}_{2} \mathrm{e} \\
(\%)\end{array}$ & $\begin{array}{l}\text { Percentage } \\
\text { population (\%) }\end{array}$ \\
\hline World & $6,670,000,000$ & 4.56 & 30.42 & 100 & 100 \\
Africa & $1,000,000,000$ & 1.70 & 1.70 & 5.6 & 15 \\
North Africa & $200,000,000$ & 4.44 & 0.89 & 2.9 & 3 \\
Sub-Saharan & $800,000,000$ & 1.02 & 0.82 & 2.7 & 12 \\
Africa & & & & &
\end{tabular}

In line with UN report on climate change and agreeable standard on millennium development goal (MDG), findings on sustainable development goal (SDG) show that carbon emission emanating from waste management and disposal are huge and much seemed not to have been achieved to 
mitigate the volume of greenhouse gasses (GHGs) [12]. The report also showed that nearly $6.8 \%$ of the GHG emissions globally are emanating from Africa contributing to ozone depletion and environmental disaster. In a similar paper published by Martindale [13], management of plastic waste globally has resulted in increasing operational cost and decreasing the available space for landfills. This has further worsened the prospects of reclamation approaches in plastic development [14].

In the time past, traditional plastics were used as potential substitute for non-biodegradable materials but studies $[15,16]$ have shown that they are not easily degradable in the ambient environments. It has been proven that plastics will remains on environments as long as lifespan of their constituents exists [17]. Polymer as a compound name for plastic generally consumes several years before it degrades and this has a lot of environmental implications [18]. Findings from Adekomaya, et al. [1] confirmed the toxicity of plastic waste involving highly toxic trace elements. Plastic waste is becoming a global crisis with no definite solution insight as its global production may exceed 250 million tonnes per year in the next two decades [19]. Plastic product utilization in India alone is approximately 12 Million tonnes as at 2012 and it is expected to exceed 20 million tonnes by the year 2025[20]. The implication of this is that more plastic waste will be generated from this process thereby compounding the $\mathrm{CO}_{2}$ emission and greenhouse gas crisis. In another paper [21], recycling of virgin plastic may no longer be a sustainable approach to plastic waste management as substantial part of the materials are completely lost after 3 to 4 times of recycling process. This may not be unconnected to the fact the strength of the recycled plastic diminishes due to thermal degradation involved in recycling process. Further studies [5] also showed that the tendency of hydrocarbon yield and distribution in the final product of plastic materials normally suffer hydrogen donor ability which is as a result of thermal loss of solvents during thermal degradation of plastic waste. The implication of this is that the overall volume of greenhouse gases being released by plastic related waste materials are much lesser that the volume of carbon released as methane gas from plastic dump site. Contrary to other researchers, their impact on climate change are equally serious as compared with emission from diesel engine driven vehicular system. Figure 2 shows the analysis of report presented by Garcia and Robertson, 2017 on embedded components materials in various plastic wastes. From the graph, the predominance of PVC, PP and PE in plastic materials further release $\mathrm{PE}$ and $\mathrm{PP}$ as domestic refuse culminating into more plastic waste.

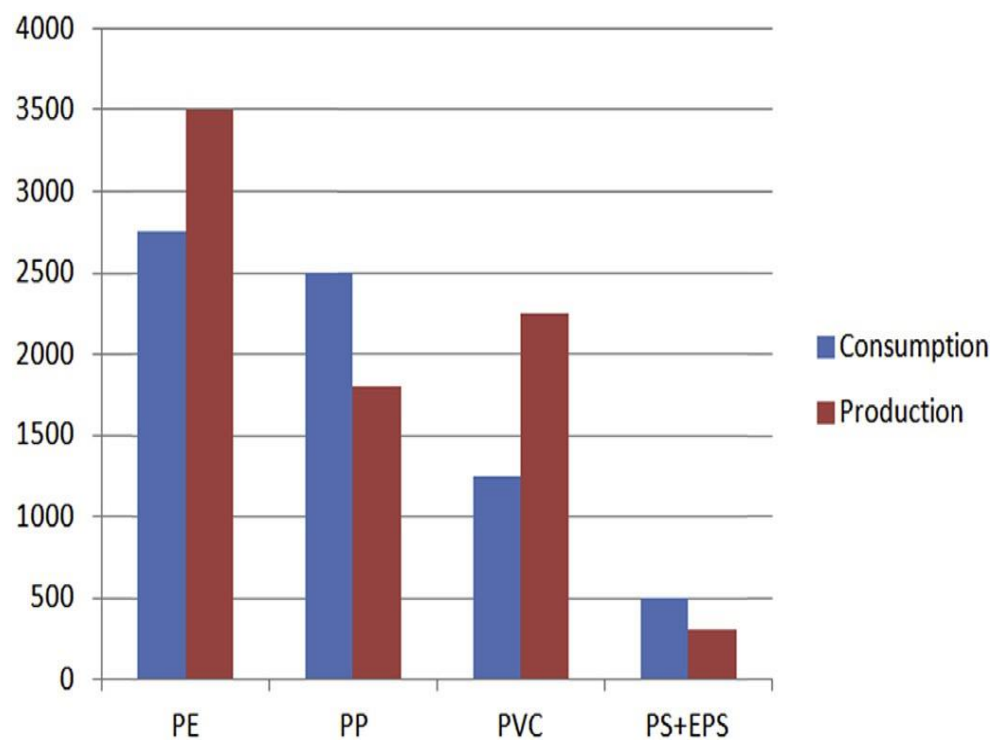

Figure 2. Analysis of plastic utilization and the evolving emergence of various plastic wastes. Adapted from [22] 


\section{Plastic Waste Emission and Evolving Challenges}

Environmental impact of plastic waste has been linked directly to the composition of the materials used for the manufacturing of plastics. This was contained in a research engineered by Salami, et al. [23] which characterize solid waste on the basis of chemical composition and preventive distribution of carbon contents on plastic materials. In another paper, Al-Salem, et al. [24] developed a novel approach to plastic waste management ranging from primary (re-extrusion) recovery process which span through secondary (mechanical) and tertiary (chemical) recovery process. They further concluded that the recovery process did not reduce the carbon contents as earlier reported in other published works. In another research paper authored by Mohareb, et al. [25], it was further revealed that management of municipal solid waste and its attendant implication on climate change will continue in view of lack of technological improvement in the existing approaches. In the analysis of data shown in Figure 3, the gross emission of land fill as management options of plastic waste is high when compared with other approaches as reported. This may not be unconnected with the net emission of waste volume generated and the possibility of increasing volume of plastic waste due to impact of waste on greenhouse gas generation. In another dimension as contained in the same Figure 3, waste generation per ton disposed appear constant for all the disposal options. This further explains the need for source reduction of plastic waste as sustainable approach to waste disposal.

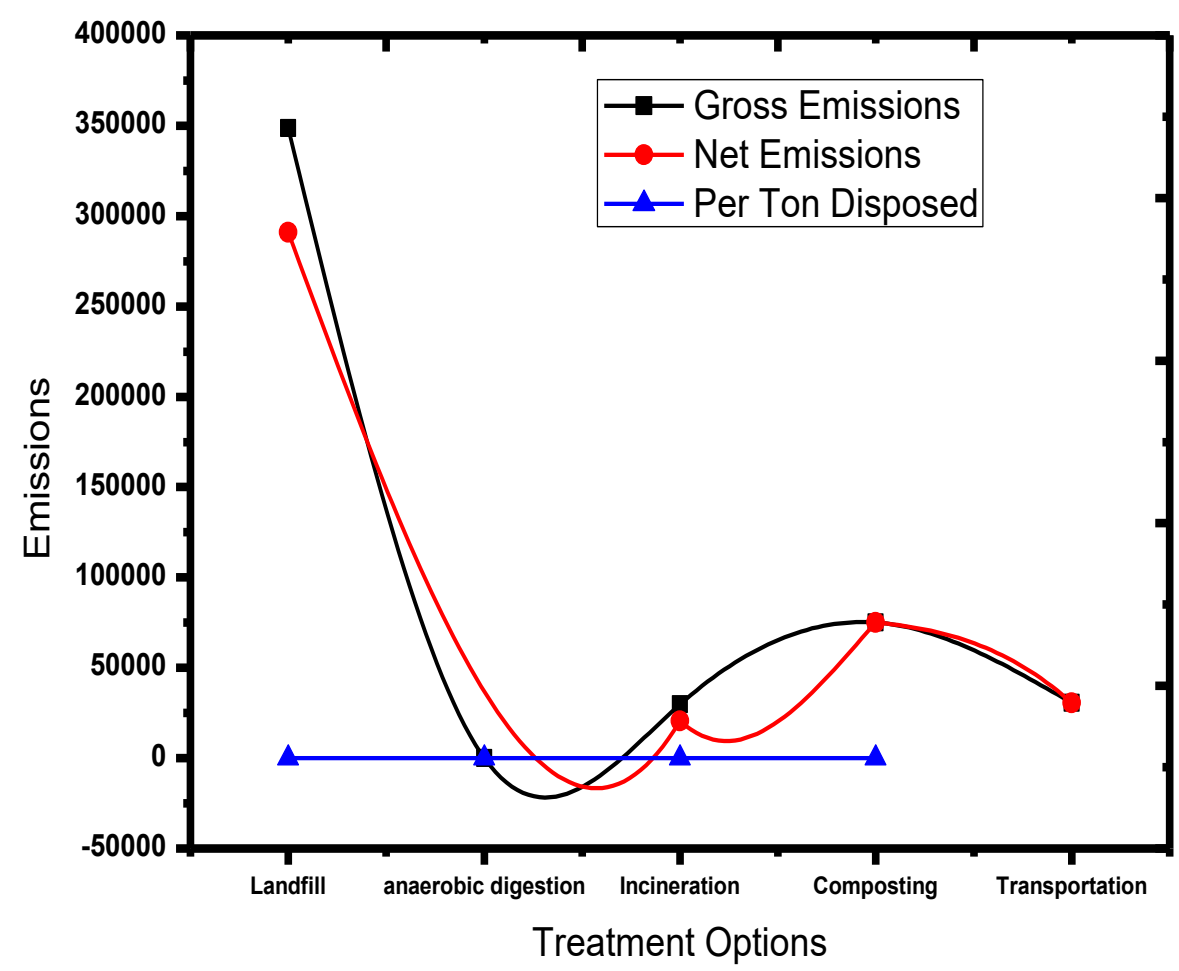

Figure 3: Contributing impact of waste plastic disposal on greenhouse gas emission. Data were adapted from [25] being a comprehensive report analysis as contained in the action plans on IPCC 2006.

\section{Conclusion and Future Works}

Plastic wastes have constituted a huge burden on the society and sustainable approach has to be developed to empirically analyse what can be done to nip the challenge in the bud. Climate change and the evolution of plastic material are highly interrelated and urgent steps must be taken to neutralize the growing impact of plastic materials on the composition of global waste. In many 
published works, wastes are generally categorised on the basis of sources and no known works have ever conducted detailed analysis on plastic waste to primarily identify the nitty-gritty of its composition. In order to determine the contributory impact of plastic waste on greenhouse gas, plastic materials must be synthesized on the basis on composition taking into consideration the geographical location of these plastic materials. Hence, further research is required to conclude such assumptions.

\section{Acknowledgment}

The author would like to appreciate various published works sourced during the write-up of this review paper. Appreciations is also extended to Olabisi Onabanjo University, Ago-Iwoye for providing the financial wherewithal which assisted greatly in this study.

\section{References}

[1] O. Adekomaya, T. Jamiru, R. Sadiku, and Z. Huan, "Negative impact from the application of natural fibers," Journal of Cleaner Production, vol. 143, pp. 843-846, 2/1/ 2017.

[2] O. Adekomaya, T. Jamiru, R. Sadiku, and Z. Huan, "Sustaining the shelf life of fresh food in cold chain - A burden on the environment," Alexandria Engineering Journal, vol. 55, pp. 1359-1365, 6// 2016.

[3] A. L. Fernando, M. P. Duarte, A. Vatsanidou, and E. Alexopoulou, "Environmental aspects of fiber crops cultivation and use," Industrial Crops and Products, vol. 68, pp. 105-115, 6// 2015.

[4] R. Marino, A. S. Atzori, M. D'Andrea, G. Iovane, M. Trabalza-Marinucci, and L. Rinaldi, "Climate change: Production performance, health issues, greenhouse gas emissions and mitigation strategies in sheep and goat farming," Small Ruminant Research, vol. 135, pp. 50-59, 2// 2016.

[5] T. Ming, R. de_Richter, W. Liu, and S. Caillol, "Fighting global warming by climate engineering: Is the Earth radiation management and the solar radiation management any option for fighting climate change?," Renewable and Sustainable Energy Reviews, vol. 31, pp. 792-834, 3// 2014.

[6] S. Upgupta, J. Sharma, M. Jayaraman, V. Kumar, and N. H. Ravindranath, "Climate change impact and vulnerability assessment of forests in the Indian Western Himalayan region: A case study of Himachal Pradesh, India," Climate Risk Management, vol. 10, pp. 63-76, // 2015.

[7] V. van Gameren and E. Zaccai, "Private forest owners facing climate change in Wallonia: Adaptive capacity and practices," Environmental Science \& Policy, vol. 52, pp. 51-60, 10// 2015.

[8] Z. Zhang, "Asian energy and environmental policy: Promoting growth while preserving the environment," Energy Policy, vol. 36, pp. 3905-3924, 10// 2008.

[9] A. Felton, L. Gustafsson, J. M. Roberge, T. Ranius, J. Hjältén, J. Rudolphi, et al., "How climate change adaptation and mitigation strategies can threaten or enhance the biodiversity of production forests: Insights from Sweden," Biological Conservation, vol. 194, pp. 11-20, 2// 2016.

[10]R. Couth and C. Trois, "Waste management activities and carbon emissions in Africa," Waste management, vol. 31, pp. 131-137, 2011.

[11] L. Rigamonti, M. Grosso, J. Møller, V. Martinez Sanchez, S. Magnani, and T. H. Christensen, "Environmental evaluation of plastic waste management scenarios," Resources, Conservation and Recycling, vol. 85, pp. 42$53,4 / / 2014$.

[12] Y. Yang and F. Xiangzhao, "Policy Options for Sustainable Development in Urban Transport: Analysis of Energy Consumption and Environmental Benefit Influenced by Different Transport Policies in Beijing," Chinese Journal of Population Resources and Environment, vol. 8, pp. 26-36, 2010.

[13]W. Martindale, "Carbon, food and fuel security-will biotechnology solve this irreconcilable trinity?," Biotechnology and Genetic Engineering Reviews, vol. 27, pp. 115-134, 2010.

[14]P. Klungboonkrong, S. Jaensirisak, and T. Satiennam, "Potential performances of urban land use and transport strategies in reducing greenhouse gas (GHG) emissions: The Khon Kaen case study, Thailand," International Journal of Sustainable Transportation, pp. 00-00, 2015.

[15]P. Biswas and C.-Y. Wu, "Nanoparticles and the environment," Journal of the Air \& Waste Management Association, vol. 55, pp. 708-746, 2005.

[16] A. Luè, C. Bresciani, A. Colorni, F. Lia, V. Maras, Z. Radmilović, et al., "Future priorities for a climatefriendly transport. A European Strategic Research Agenda towards 2030," International Journal of Sustainable Transportation, 2014. 
[17] O. M. Amoo and R. L. Fagbenle, "Renewable municipal solid waste pathways for energy generation and sustainable development in the Nigerian context," International Journal of Energy and Environmental Engineering, vol. 4, pp. 1-17, 2013.

[18] G. Oliveux, L. O. Dandy, and G. A. Leeke, "Current status of recycling of fibre reinforced polymers: Review of technologies, reuse and resulting properties," Progress in Materials Science, vol. 72, pp. 61-99, 7// 2015.

[19] L. Yang, E. R. Sáez, U. Nagel, and J. L. Thomason, "Can thermally degraded glass fibre be regenerated for closed-loop recycling of thermosetting composites?," Composites Part A: Applied Science and Manufacturing, vol. 72, pp. 167-174, 5// 2015.

[20] N. Reddy and Y. Yang, "Biofibers from agricultural byproducts for industrial applications," Trends in Biotechnology, vol. 23, pp. 22-27, 1// 2005.

[21] B. Phalan, A. Balmford, R. E. Green, and J. P. W. Scharlemann, "Minimising the harm to biodiversity of producing more food globally," Food Policy, vol. 36, Supplement 1, pp. S62-S71, 1// 2011.

[22] J. M. Garcia and M. L. Robertson, "The future of plastics recycling," Science, vol. 358, pp. 870-872, 2017.

[23] L. Salami, A. Susu, R. Patinvoh, and O. Olafadehan, "Characterisation study of solid wastes: a case of Lagos state," International Journal of Applied Science and Technology, vol. 1, 2011.

[24] S. M. Al-Salem, P. Lettieri, and J. Baeyens, "Recycling and recovery routes of plastic solid waste (PSW): A review," Waste Management, vol. 29, pp. 2625-2643, 10// 2009.

[25]E. A. Mohareb, H. L. MacLean, and C. A. Kennedy, "Greenhouse gas emissions from waste managementassessment of quantification methods," Journal of the Air \& Waste Management Association, vol. 61, pp. 480493, 2011. 